\title{
Zur kontinuierlichen Ermittelung des spezifischen Gewichtes
} von Destillaten im Fabrikbetriebe haben H. Mittler und L. Neustadtl ${ }^{1}$ ) eine Vorrichtung konstruiert, die zum Patent angemeldet ist. Sie besteht im wesentlichen in einem Zylinder, der von einem Teil des Destillates dauernd durchflossen wird. In diesem Zylinder befindet sich ein Thermometer und ein Aräometer, so dass man immer sowohl die Temperatur als auch Dichte und Farbe des Destillates beobachten kann. Für Öle, die mit Dampf destilliert werden, ist ein Wasserabscheider angebracht.

Über einen Apparat zur Stickstoff bestimmung berichten $\mathrm{Ni}$ i ol a $\mathrm{S}$ und Deland. ${ }^{2}$ ) Porscher und Brisa ${ }^{3}$ ) hatten früher einen Apparat zur Zersetzang von Ammonsalzen mit Natriumhypobromit angegeben, dessen Besonderheit darin besteht, dass es möglich ist, während des Versuchs neue Flüssigkeit zufliessen zu lassen.

Dieses Instrument haben $\mathrm{Nicolas}$ und Deland nun verbessert, indem sie das komplizierte and leicht zerbrechliche, auf den Zersetzungskolben aufgesetzte Mittelstück ausschalten und den Kolben durch einen doppelt durchbohrten Stopfen verschliessen. Durch die eine Öffnung geht eine Verbindung nach einer mit Glashahn versehenen und die Hypobromitlösung enthaltenden Flasche, welche nach aussen abgeschlossen ist und einen seitlich angebrachten Stutzen besitzt. In diesem ist der eine Schenkel eines T-Rohres befestigt, dessen zweiter Arm nach dem Gasmesserrohr führt und dessen dritter mit der zweiten öffnung des Zeretzungskolbens verbundon ist. Auf diese Weise stehen alle Teile des Apparates unter sich in Verbindung und sind von der atmosphärischen Luft abgeschlossen; aus diesem Grunde ist ein Nachfüllen der Hypobromitlösung möglich, ohne dass eine Volumenänderung im Inneren des Apparats verursacht wird.

Einen neuen Spektralbrenner haben E. H. Riesenfeld und H. E. Wohlers ${ }^{4}$ ) konstruiert.

Die Verfasser benutzen das zuerst von Lockyer ${ }^{5}$ ) angegebene Prinzip, den zu untersuclıenden Körper durch einen Zerstänber der nicht

1) Chemiker-Zeitung 30, 1023.

2) Annal. chim. analyt. 10, 7; durch Zeitschrift f. Untersuchung d. Nahrungsn. Genussmittel 10, 691 .

3) Zeit.chrift f. d. Cntersuchung d. Nahrungs- u. Genussmittel 7, 282.

4) Chemiker-Zeitung $\mathbf{3 0}, 704$.

5) Studien zur Spektralanalyse, Leiprig 1879. 